\title{
REPRODUCTION, ETHICS AND HERITABLE DEAFNESS: THREE SOUTH ISLAND FAMILIES EXPRESS THEIR VIEWS
}

Ruth P Fitzgerald, Hayley Bathard, Rosie Broad, \& Michael Legge

ABSTRACT

Three consenting South Island (New Zealand) families with experience of living with a heritable type of deafness undertook a series of open-ended interviews to ascertain their own views on reproductive decision-making and genetic testing. All the families had undergone genetic testing, however their orientation to testing in general was cautiously negative. They did not regard deafness as a suitable reason for considering the termination of a pregnancy, although some of the younger adults gave some hesitant consideration to the 'right to choose' for others, while rejecting this for themselves. The families were adamant that deafness was not a disability but rather an inconvenience and only so because a disabling and audist society created certain obstacles in the pathway to achieving good schooling, employment and quality of life.

\section{BACKGROUND}

In 2002, Sharon Duchesneau and Candace McCullough gave an interview to the Washington Post in which they discussed their attempts to use donor insemination to select in favour of embryos that would be D/deaf (BBC News 2002). Around the same time as this, a UK researcher (Middleton 2004) conducted a survey of British $\mathrm{D} /$ deaf and hearing in which a very small number of respondents indicated that they would consider using prenatal genetic testing to select against the 'wrong' type of baby - either hearing or D/deaf - depending on each person's perspective. The global publicity around these two events promoted, we suggest, the recurring trope of selecting for $\mathrm{D} /$ deafness in bioethical debates between so called 'designer babies', reproductive ethics, the idea of a 'good' life and the rights of children (Savulescu [2002], Spriggs [2002], Parker [2007], Shaw [2008], Ralston and Ho [2007], Sabatello [2009], Fahmy [2011]). Currently in New Zealand, the decision to select against reproducing certain impairments is the only legal response to this issue (HART Act 2004) 
and once again, this stance is defended explicitly via reference to the deafness selection debate. Consider the following advice to the Minister of Health on the ethical uses of a type of genetic test known as PGD from the government ethics committee ACART (ACART 2008:4-5) which states:

\begin{abstract}
...the use of PGD to select deaf embryos is being debated in the United Kingdom, as legislation currently before the House of Commons would not allow a deaf woman or couple to use PGD to ensure they have a deaf child.... in its consultation document, ACART proposed that PGD must not be used for the purpose of selecting an embryo with a genetic disorder. Most submitters commenting on this point were supportive.
\end{abstract}

Given this persistence of genetically heritable D/deafness as a reference point in philosophical debates around testing, disability and reproductive choice, our project's aim was to gather empirical comparative evidence of the views of such uses of genetic testing from families who had direct experience of this situation. By seeking to ground abstracted ethical arguments against lived experience (an approach also suggested by Scott and Du Plessis [2008]), our work forms one component of a larger Marsden ${ }^{1}$ funded project that explores everyday ethical thinking around reproductive decision making for genetic difference. Best et al (2013) presents further findings from an associated parallel study to this that ran concurrently in the North Island of New Zealand. Taken together, these two projects contribute to the further elucidation of a New Zealand style of engagement with genetic technologies (see also Scott and Du Plessis [2007], Fitzgerald [2008], Du Plessis and Fairburn-Dunlop [2009]).

Internationally, there are contradictory findings on the acceptability of genetic testing for heritable D/deafness. For example, Taneja et al (2004) in a U.S. study based on anonymous questionnaires of 77 students at a US based liberal arts college for $\mathrm{D} /$ deaf students found $72 \%$ of participants were neutral rather than negative about 'advances in genetics'. Views on genetic testing for $\mathrm{D} /$ deafness at birth were less clear cut with nearly equal numbers of participants in the categories 'unsure,' 'yes', and 'no'. By way of contrast, the early large scale survey work in the UK by Middleton (2004) demonstrated a good deal more negativity on the topic of genetic testing from $\mathrm{D} /$ deaf rather than hearing participants than was the case in the US. Even so, in both groups only a very small percentage of participants would have considered terminating a pregnancy for the 'wrong' hearing status. A subsequent U.S. study by Burton et al (2006) based on the opinions of 44 participants including hearing parents of deaf children, deaf 
parents and young deaf adults; spoke favourably of genetic testing. However the familiar concerns that genetic diagnosis might cause terminations were also noted. Reasons for the positive response to testing from hearing parents in this study was the help this gave them in accepting their children's condition. For D/deaf parents, the reason was to do with curiosity as to why they were deaf. A different survey conducted by Ryan et al (2003) based solely on hearing mothers at a Scottish maternity hospital, was designed to elicit their willingness to pay for a D/deafness carrier screening test. This pool of hearing mothers is more like the wider group of people to whom children with heritable D/ deafness are born - those with little knowledge of the social experience of D/ deafness and with very little time to adjust to the identification of $\mathrm{D} /$ deafness in their child. The mothers' response was that $74 \%$ were interested to know if they were a carrier for $\mathrm{D} /$ deafness and would pay a mean of 42 pounds for such testing, however only $7 \%$ considered that they might terminate a pregnancy for D/deafness of the fetus.

More recently, Fu et al (2010) analysed 290 self completed surveys from participants at a conference held at a Chinese based research centre for D/deaf children. The authors found a very positive attitude towards genetic testing for prelingual deafness. They note that $72 \%$ of respondents wished to test a deaf child (again, often to know the reason for the deafness) and 91\% wished to find out if they would bear another deaf child. However the paper cites only 'a few' of the respondents indicating that they would terminate a D/deaf fetus. A recent six month longitudinal study in the US by Boudreault et al (2010) of $256 \mathrm{D} /$ deaf adults recruited from the state of California found strong interest in genetic testing to explain the reason for one's deafness and other reasons related to self and family, as well as to promote research in deafness. However there was very little interest to use the testing for selecting a partner or to decide whether or not to have children. The study tracked (using questionnaires) participants' responses before and after engaging in genetic testing. The results were the same regardless of affiliation to the D/deaf community, or the hearing community or both; although cultural affiliations did correlate with slight differences in the total number of reasons for testing. While one might be tempted to infer from these studies that attitudes towards genetic testing are becoming more positive, the reality is that decontextualised data from questionnaires from such small numbers of people over such widely disparate cultural backgrounds and economic opportunities makes for a very weak data base for interpretation. For this reason, our study is localised and small in scale, prioritising richness in the data sample rather than geographic coverage of a population. 
METHODS

Ethical approval for this project was obtained via the University of Otago Human Ethics Committee (Category A) approval number 10/110. Anonymity within a small community such as the New Zealand D/deaf and hard of hearing is difficult to achieve and was not particularly desired by the participants, however we have avoided the use of real names in this publication. The study was conducted from November 2011 until February 2012 with the second and third (hearing) authors as the interviewer, supervised by the first (hearing) author. The fourth (hearing) author contributed expertise in the biological science of genetics. The participating families were invited into the study via liaison with a well known member of the New Zealand D/deaf communities who advertised details of the research project widely. The participating student researchers were selected following advertisements within medical anthropology classes at the University of Otago. All workers on the project undertook a week's training in advanced ethnographic methods held at the University of Otago and subsequent to participating in the project, both student researchers have taken up sign language classes.

Each family contained members who were hearing as well as members who were $\mathrm{D} /$ deaf with some of these family members also making use of assistive hearing technologies. One family used New Zealand Sign Language (NZSL) as their preferred communicative strategy. All families understood the deafness within their families as having some genetic basis. In total, three interviews were conducted with Family A, two interviews were conducted with Family $\mathrm{B}$ and five interviews with Family $\mathrm{C}$. These interviews were open ended in nature with topics drawn from a schedule covering the following areas: personal understandings of reproductive choices in relation to the identification of deafness; the meaning of disability; the significance of genetic testing; the public debates over genetic testing; and tensions and commonalities between moral reasoning on these issues within the family and within society.

The resulting research conversations varied in length from thirty minutes to two and a half hours and were analysed for common themes using an open coding approach (Hammersley and Atkinson 2007). Participants had an opportunity to comment on the findings and correct introduced errors and wording. The particular focus in all of these interviews was to observe and converse with people as a family on this topic, thus all researchers met with the wider family as part of the study design and visited the families in their homes on several occasions. 
RESULTS

\section{Thoughts on D/deafness and disability}

For all of the families, to be deaf was to experience just one more aspect of ordinary human diversity. At the most negative, it was spoken of as an annoying problem that interfered at times with socialisation. Families also recounted the difficulties for schooling that were frequently associated with deafness, however in such circumstances, the disabling aspect of deafness was located within hearing society (drawing on a social model of disability). The type of deafness that was inherited through Family A was very well known and widely dispersed through the extended family. In general, affected family members were all born hearing although their hearing tended to diminish in school years, sometimes in association with antibiotics, or later with child bearing. The $\mathrm{D} /$ deaf women in the family would bear D/deaf children and the D/deaf men would not. Deafness was thus entirely normal within the family and well understood which, as the mother pointed out, made them quite atypical in their experiences of deafness:

Its different from most, because I'm deaf myself. For me it's not... for me it's not like 'Oh my God!' it's like 'OK, you get on with it!' You help them (the children) as much as you can. I do understand if its deaf children and they [the hearing parents] have only just found out, they're absolutely gutted, they're devastated and everything else.

The family saw themselves as sitting on the fence between the Deaf and hearing worlds and able to access each community without feeling on the fringes of either. Contributing to their 'sitting on the fence' position was the decision in the family for all deaf members to obtain cochlear implants when their hearing dropped to unmanageable levels in adolescence. If the hearing device was removed however, the family members became completely $\mathrm{D} /$ deaf as the father (the only completely non deaf member of the immediate family) observed laughingly: 'It's quite annoying in the morning because nobody puts it on first thing, they're all quite chatty then and of course they can't bloody hear me (the family joins in laughing)!' Sharing this easy familiarity with deafness meant that family members also shared strategies in working around some of the annoying aspects of their deafness. The mother discussed how she made her decision to get a cochlear implant after waiting to see how her relatives found the procedure and whether they received any benefit:

When they (cochlear implants) first came out, I was sort of umm- 
ing and ahh-ing and then my sister said she was getting one. So, I thought 'OK, I'll watch you and see what happens', and then I saw what a change it made! I was like 'Nup, [without a doubt] I'm getting one'. So it's always the person who makes that first step whom you watch, and you follow, so now there's ten of us who've got them in my family.

Family B also had an easy acceptance of the normality of deafness which in their case had arrived as something of a surprise for a family in which apart from their youngest child, all other members were hearing. As noted in Best et al (2013), this is a far more representative experience of how the majority of people encounter heritable deafness. This family used NzsL for primary communication with their youngest child and the normality of D/deafness was underscored by recognising it as membership within a different language and culture group - an experience to be respected and embraced. While being D/ deaf did 'have its issues' as the mother noted, 'you just need to figure out how to get around those obstacles really' and the family's wholehearted uptake of NZSL was one such response. The father, when prompted to speak about D/ deafness in relation to disability argued 'I see being D/deaf in a hearing society [as] being a disability, but that's because hearing society is disabling, through their ignorance and through their lack of wanting to communicate.'

Family $\mathrm{C}$ also agreed with the other families that D/deafness was not a disability but rather it was just a case of 'things have to be different for people with deafness'. In Family C, several children had been hard of hearing from birth and lived with varying episodes of hearing level 'dropping' suddenly and then later returning. Within this large family being hearing or being $\mathrm{D} /$ deaf was simply a matter of 'what happened to come along' with each joyfully anticipated birth. This family were primarily oral/aural in their communication strategies with some but not all of the children who were hard of hearing choosing to take up cochlear implant technologies. Again the only context in which the family could view deafness as a disability was in relation to a disabling and audist society as when the father mentioned how it was the incapacity of the education system to properly school D/deaf children that was disabling. He argued that the lack of adequate schooling was then reflected in lesser job opportunities and poorer earning capacity. Thus the social model of disability predominated in relation to D/deafness ie the disability was created via society's disinterest and lack of involvement in $\mathrm{D} /$ deaf people's worlds. As one daughter mentioned 'if you [could be involved] in the D/deaf community, you might see that it's not that big a deal [to be D/deaf] ...people live with it easily', while the mother emphasised that deafness was a cultural identity. One 
son in Family C (who used a cochlear implant) took a slightly different meaning on the nature of $\mathrm{D} /$ deafness by suggesting that it was not a disability as there were ways of dealing with it by correcting it. He offered as an example, putting effort into supporting children who are D/deaf - in the forms of technology, support, and speech development. However, even working with this slightly medicalized approach to understanding the nature of $\mathrm{D} /$ deafness (in the sense that it was something to be remedied) he was also keen to note that at most 'it can be really annoying' and with some support, 'you can deal with other people fine'.

\section{Some difficulties of living in an audist society}

Encountering disabling attitudes where people put limits on the abilities of $\mathrm{D} /$ deaf people, or the need to face stigmatising attitudes was raised by all. For example, the daughter in Family A was bullied at primary school for being deaf. While the teacher overheard the bullying and told the offender to write a note to the young girl to apologise, the memory was still vivid of the bully's foul language - 'deaf bitch' and so on. The intensity of that memory from childhood was partly explained as mother and daughter commented upon how they can feel if someone is making fun of them.

Daughter : ...so with me it's a little bit harder because I can hear they're making fun of me and I know they're saying things and making fun of me, whilst my other deaf friends might not entirely be aware they're being made fun of.

Mother:... you also go by body language as well, sometimes that's really horrible and you can actually feel it, body language and facial expressions are something that can be really hurtful for deaf people as they are used (in place of verbal tone) to assess a person's mood or demeanour, You can almost feel it, it's horrible. It's really hard to explain.

Isolation was also an issue surrounding deafness, both for those who are deaf themselves and for their families. Family B for instance, kept to themselves for a while after discovering their child was deaf, at times finding it difficult to interact with others or to deal with people's reactions to her deafness. Their friends similarly struggled to know how to deal with the situation and visits tended to drop off. The father felt particularly isolated as the stay-at-home parent trying to learn a new language (NZSL) to communicate with their daughter. He commented: 
Yeah so there was a lot of isolation, for me. I deliberately isolated myself at times because I had to process it, and nobody else could help me process it, because nobody else had gone through it. It's not like going to an AA meeting or an NA meeting where everybody's sitting there saying 'Well hello I'm an addict, I'm just like you'. You know, it's not like that. And because of our choice to bring her up in Deaf Culture, you know, I couldn't talk to other parents of D/deaf because they hadn't chosen that. So like I said I'd go along and talk to the D/deaf, they're different again-they're D/deaf and I'm hearing.

With time, however, this isolation eased, and their child's D/deafness and the presence of a new language and culture in their household became normal. On the other hand, their daughter experienced some social isolation as the only $\mathrm{D} /$ deaf pupil in the roll of 750 high school students. Outside of school, with few family members and friends being fluent in sign language, this trend continued. Her father noted: 'She's got a friend who's 14 who signs and there's a little boy who's about 12, so really, as far as children and signing goes, that's it pretty much for [this city].

Family $\mathrm{C}$ had not encountered the same levels of isolation as Family B but it had certainly caused some concern. The mother noted that education was originally, for her, the paramount issue with regard to her children's D/deafness by a clear margin. In fact, fighting for equal educational opportunities emerged in every family's story. However, she has become increasingly worried about the issue of social isolation and she acknowledged that all three of her children who are $\mathrm{D} /$ deaf experienced it to some extent.

\section{Communication and assistive technologies}

Family B were initially told that Signed English was the only form of communication available for them to use with their profoundly deaf daughter:

So when we were being told that the mode of communication that we would be using was Signed English I said 'Well, ok', you knowbecause I knew no different. But when I started questioning what the D/deaf of [this city] used, it wasn't Signed English, it was New Zealand Sign ... and then when they said that Signed English was a made up language by hearing people to communicate with the D/ deaf, I thought: 'Oh OK, right, we won't be having that then!' [Laughs]

NZSL was not at all widespread at the time that this family wished to use it, 
even within the $\mathrm{D} /$ deaf community, as sign language had been banned for many years at van Asch and the pupils were expected to be oral. Thus in order to gain access to NZSL, the father attended a Mother's Group of D/deaf mothers and recalled their fascination in a hearing parent teaching their D/deaf child to sign. Both parents remarked that learning NZsL was a difficult process, as it was not at all intuitive to be communicating with their child in a totally new language. They considered that their struggle for access to sign language has been the hardest and most ongoing struggle that they have faced with their $\mathrm{D} /$ deaf daughter. Together, both were critical of the status of sign language in New Zealand, despite its status as an official language, and while they have been lucky in having some good teacher aides for their daughter over the years, at times, their daughter has been more proficient in the language than her teacher's aide.

Even so, Family B had never considered a cochlear implant for their daughter, mentioning the high expectations that often accompany them, and the fact that these would not always be met. In addition to this, at the time that doctors discussed the implants, the technique was still quite new, and both parents were concerned that their daughter's operation would be experimental. However, by refusing a cochlear implant, the parents were confronted with disapproval, with some folk suggesting it was cruel to reject an implant. Disturbingly, the hospital also 'washed their hands' of the family once they had rejected the implant and never made contact again. In the present day, the mother spoke about the time pressure that parents are often put under to make decisions about cochlear implants. She observed that new parents are still often not fully informed about deafness, and tended to have little knowledge about what it is like to be deaf as they mostly did not have any contact with the D/deaf community before they made decisions for their child.

All families were aware that cochlear implants have caused controversy within the D/deaf community since their introduction. However the different circumstances in Families A and C meant that both of these families had taken up the technology. Family $\mathrm{C}$ noted some improvement in communication when two of the three children who are D/deaf were fitted with cochlear implants-resulting in much less stress in their household. Previously the family had to speak loudly and clearly all of the time and because of the extra effort required, this sometimes limited explanations of difficult concepts. However even with the assistive devices there was still a need to speak directly and with some repetition to those family members who are $\mathrm{D} /$ deaf. The mother in this family also noted in a later email her conflicts regarding cochlear implants. For instance, she wrote: 'they are a huge improvement on hearing aids and are therefore of 
great benefit for those people who are suitable candidates and wish to have them. In the wider D/deaf community, she considered there had been a softening of attitude towards cochlear implants, so that folk no longer considered them to be a judgment on $\mathrm{D} /$ deaf people as though they were somehow in need of fixing. However the mother also held no doubt that their widespread uptake is likely to be cultural genocide as they have the effect of decreasing the pool of people who are highly proficient in NZsL.

The young $\mathrm{D} /$ deaf man interviewed from this family spoke very positively about his cochlear implant, stating that he was content with the decision that his parents had made for him, although there were a few minor hassles with cochlear implants. He also mentioned, '...the odd malfunction which is really disturbing. One morning last year I woke up and my hearing was really weird, it was different. And I couldn't go to class for two or three days'. Despite these shortcomings, the implant had had a positive impact on his experiences at school. He reflected:

Well it's improved my quality of life, I would say. Very much so. I mean, I'm not sure I could cope with hearing aids solely. And I would be bored to death with only being able to sign to the same old people. You know, it would be very restricting to be kept to one circle. It isn't very big in [this city] anyway-I would need to move to Christchurch to meet more deaf people who can sign. So I think [the] cochlear implant, my one, has given me the chance to go and experience life properly, go and meet new people.

Other, more generalised types of new technology, have also worked in the favour of the D/deaf. Family B, for example, noted that the social networking sites offered their Deaf daughter plenty of opportunities for conversing with peers. Family $\mathrm{C}$ appreciated computers and cell phones. This was because spelling and grammar - aspects of spoken English language that deaf people often struggle with - do not matter as much in emails and text messaging. Family A enthused about texting for the way that it greatly increased independence. They were also pleased with high quality internet conferencing technologies with better quality visuals than Skype allowing people to communicate via sign, although the cost of this equipment was prohibitive. The mother in Family A added:

I think cochlear implants are the best things since sliced bread, and I wish that they were available when I was young. I really would have benefitted from it when I was at school. If I could go back and do 
what [my daughter is] doing now, God it'd be so good. I think there's still challenges for deaf children of hearing parents, that's very, very hard... Not a lot of help out there, especially when they don't talk and they rely on sign language. So I think we are pretty lucky...

This family also wished that the New Zealand government would fund two implants (as occurs in Australia) rather than only one.

\section{Genetic Testing and Reproductive Decision-making}

Genetic testing proved to be a controversial subject amongst both Families $\mathrm{B}$ and $\mathrm{C}$, in which the senior family members felt very strongly against its use. Words like 'wrong,' 'worrying' and 'against nature' came up frequently in conversation. Genetic testing was often linked conceptually with consequent termination of pregnancy, contributing to the rejection of its use, and an intervention considered particularly unjustifiable for deafness.

The father in Family B voiced concerns over the fact that testing led to society choosing between right and wrong with no basis other than negative stereotypical thinking in presuming deafness to be 'wrong. He compared the termination of pregnancies of deaf children to cultural genocide and eugenics.

The mother in Family $\mathrm{C}$ had similar views:

I think it's a really rocky road...it's about people making judgements that they have no right to make. That, for instance, if it was decided that Pendred's [a type of heritable deafness] was an undesirable, or even like Down syndrome, you know, I mean who the frick has the right to decide the value of a life, you know, it's just, personally I think it's wrong.

The mother in Family B agreed:

Well personally, that would be... it would have to be a way more serious birth defect to... justify termination. You know, deafness isn't the end of the world [laughs] - you know, people live happy, productive lives being deaf. Yeah, it's not a disability so yeah, it's a weird one isn't it? That whole genetic testing to sort of eliminate what is perceived by some people as not being... perfect. But who's to say what's perfect - you know, who's perfect and who's not?'. 
The younger participants in Family $\mathrm{C}$ tended to be slightly more open to the idea of genetic testing, with individual's choice being a major factor in their views. However, all noted that they did not think they would use it themselves, especially in relation to $\mathrm{D} /$ deafness. As one daughter stated:

I'm really in two boats on that one. I can definitely see the advantage but I think that if people don't fully understand the situation then they might jump to a conclusion too hastily ... it's a bit... of a double edged sword.

One of the sons who was hard of hearing, spoke of the effect that genetic testing could have on the child in question, noting that it can portray ideas of perfection as he grappled with the feelings a child might have if $s /$ he were to find out their parents had undertaken genetic testing.

The Deaf members of Family A were not as familiar with current ethical debates on genetic testing although they were interested in the genetic basis of their type of deafness. They had, for example, willingly assisted a scientist in an attempt to identify the genetic location of their deafness and they held a good functional knowledge of the reasons for their deafness. Passing on D/ deafness was something that all members of this family had to explore when they decided to have children. As no-one in the family considered that their deafness was a disability, they especially did not consider it to be a reason that would warrant not having children or (given the mitochondrial inheritance pattern of their D/deafness) only having sons so as not to pass on the deafness to their grandchildren. That anyone might entertain such thoughts was both disturbing and very odd. The participants on reflection, however, could see some benefit to genetic testing (ie for hearing couples wanting to have children), as this might enable such parents to cope better with the arrival of a deaf baby by giving them some additional time to start educating themselves.

Family members also agreed that should they ever be in such a position that they would not try to deliberately have $\mathrm{D} /$ deaf children by specially selecting them. The reason for this was that while they have come to accept their deafness as part of their lives and identities, they also wouldn't wish their deafness on anyone. Although they also noted that there are many causes of deafness and genetics is but one of several.

Interviewer: What do you think about people who might want to test to make sure they have only deaf children? 
Mother: What?! Why would you want that?! I've heard that too. I've been told actually that I'm lucky I've got deaf children, from my deaf friends.

Interviewer: $\mathrm{mhmm}$, yeah.

Daughter: [questioning her mother's friends' meaning] if you think about a deaf mum having a deaf child, she might get jealous that the child's hearing is better or ...?

Mother: No, I think it's a sense of being the same as me, you know? I mean it's not something I'd wish on somebody.

[and, in a later conversation]

Mother:... And as [my daughter] says, if they were going to bring in genetic testing for every woman to find out if there was something wrong with the baby, you know? If they were going to identify Downs Syndrome [and terminate the pregnancy, then] I think society would be a pretty hard going place - there would be nobody with a heart.

For all of the families, the ethical issues around parenting children who were $\mathrm{D} /$ deaf were decidedly not about whether or not to have such children, but instead were over the pragmatic concerns regarding the difficulties of obtaining a high quality education for one's children, the dilemmas of knowing when to consider a cochlear implant, and the problems that children would sometimes face when engaging with stigmatising community attitudes.

\section{DISCUSSION}

A culturally and methodologically relevant study to compare with our findings is the Australian study by Guillemin and Gillam (2006). The research is based on in-depth interviews with nineteen participants recruited from various $\mathrm{D} /$ deaf community groups, support organisations and learning centres. The interviews were conducted in both signed and spoken Australian English with results analysed via a grounded theory approach. The results showed participants had favourable opinions about genetic testing with a very strong proviso that such testing must be undertaken in an environment that provided high quality and useful information about living as a D/deaf person. This sentiment 
was echoed strongly by the participants in our own study. Prenatal diagnosis was regarded by most as a positive intervention that could allow for better planning for children's schooling and language needs as well as an opportunity to further research into deafness. The majority of the Australian study participants did not consider that terminations were an appropriate response to a D/deaf fetus although five interviewees recognised a need to respect other's choices. One of the participants had made the decision to be tested while pregnant however because the fetus was hearing, no termination was undertaken, and a further two were simply 'unsure.' This study also emphasised the hidden complexity behind assigning opinions to certain community groups such as D/ deaf or hearing and the need to gather context rich opinions from folk about their views on these topics. For instance ideas for or against prenatal testing in the Australian study could not be predicted according to whether one expressed allegiance to the D/deaf or hearing community. Finally, the study participants noted the world of difference between being in an actual situation in real life versus imagining it - again there was a similar recognition of this from the families in our own study.

Steinberg et al (2007) conducted similar research in the US with English and Spanish speaking and signing participants. Again the interviewees revealed similar complexity of thinking on the issue of genetic testing with none of the twenty-four parents considering that terminating a pregnancy was a reasonable response to a D/deaf fetus although eleven considered genetic testing to be a positive thing. Some of the reasons for this positive endorsement of genetic testing were the ability to then prepare in advance for schooling and medical interventions. Study participants with familial D/deafness, or those overwhelmed by the responsibilities of attending to the care of a D/deaf child, saw testing as less relevant. Many of the parents pursued testing simply because their doctors requested the test.

To what degree then did participants in our own study experience coercion from the institution of medicine to take up testing or to regard themselves in medicalised terms as 'having a deficit'? While all families had undergone testing, such decisions did not equate to an acceptance of genetic testing as a positive social contribution. Instead, these South Island families had many more reservations about testing technologies than the international studies have noted. In terms of direct pressures from medicine to accept the deficit model of D/deafness, it is Family B's experience of never being called back to the hospital for further attention to their child's D/deafness after refusing a cochlear implant that provides the clearest example of this. The hospital care being offered to them, it would seem, was articulated only through a medical 
model of disability. Such a view conceives of D/deafness not as one of the most common forms of ordinary human difference (Kochhar, Hildebrand and Smith 2007) but rather as a lack of hearing - a type of pathology in need of correction. In line then with this, the institution of medicine creates expectations that 'good' patients who are D/deaf will follow the requirements of Talcott Parson's famous sick role model in which the D/deaf would be required to take all possible steps to 'get well' including removing themselves of their deafness via technology (Parsons 1971). Family B's experience revealed the incapacity of the hospital staff (on this occasion) to imagine any other type of care paradigm.

While Family A and some members of Family $\mathrm{C}$ had taken up cochlear implant technology, it would be quite incorrect to assume that they had also taken on a medicalised model of D/deafness. They soundly rejected any model of themselves as disabled (as did Family B). Family A regarded their shared family experience as far more compelling than any medical authority in decisions to take up these hearing devices. In Family $\mathrm{C}$ not all children had chosen to be fitted with a cochlear implant but again, the opportunity to have several children in such a situation allowed for comparison and discussion and an opportunity to learn from experience. The desire to excel academically also came through as one of the reasons for considering taking up the technology in both of these families. Mckee (2006) and Noble (2006) provide additional New Zealand examples of the difficulties in receiving high quality schooling when $\mathrm{D} /$ deaf.

Another reason cited by members of both families in favour of these technologies, was the social isolation associated with being completely reliant upon the very small group of folk in the South Island who were competent signers. In a related but quite separate South Island study by Clift (2012) exploring the views of members of the Church of Jesus Christ of Latter-day Saints on genetic testing and disability, Clift quotes a young Deaf adult on the same topic. The young man comments that his social isolation was only ameliorated by moving overseas to a much larger Deaf community as a young adult. In contrast, Broad's honours dissertation which follows up more remotely located members of Family A in the South Island reveals that living in very small, country towns can be far less socially isolating (at least in terms of experiencing less stigma) when D/deaf, than a larger country town (Broad 2012). The smaller towns were more accepting, as 'everyone knows your story', although they cannot sign. Thus the effects of demography on social isolation for the signing $\mathrm{D} /$ deaf may be rather complex. It might also be that the frequent references in interviews to the South Island D/deaf community as being far more aural/ oral than the North Island D/deaf community reflects something of its different demographic makeup. By this we mean the smaller base population of 
the South Island from which to produce a community of signers. This is then coupled with there being only one large population centre capable of attracting a significantly sized signing community. Added to this, one must consider the recognised pattern of a large number of $\mathrm{D} /$ deaf children being born to hearing parents who have little knowledge of the long social history of the $\mathrm{D} /$ deaf community and the result might be a press towards being aural/oral. Socialisation into D/deaf communities, Smiler (2006) explains, is not automatic because $\mathrm{D} /$ deaf people experience $\mathrm{D} /$ deafness or their own hearing impairment differently. For example, many Maori D/deaf people (Smiler 2006:118) find it difficult to navigate avenues to access the D/deaf community which has been historically stereotyped as a homogenous community.

The degree to which medicalized constructions of $\mathrm{D} /$ deafness are being created in the contemporary New Zealand health care system is relevant to the study of ethical responses to genetic difference. However it is not possible to judge this from our own project - despite one family experiencing such a situation in a tertiary hospital - as our sample size is too small and does not include a systematic survey of this topic across medical institutions in the South Island. An obvious point of enquiry in such a project would be SCIP which is a referral point in the South Island for cochlear implant technologies. Broad (2012) discusses some of these issues with members of SCIP. She notes that although SCIP presents a highly medicalized website, in her brief conversations with its staff members, SCIP workers had a balanced and much more inclusive construction of the meaning of $\mathrm{D} /$ deafness than a deficit-based medical model. The recently published audit of referrals to SCIP (Bird et al 2010) also displays some sensitivity to the cultural values of the New Zealand D/deaf Community in the review by SCIP of referral patterns for their services.

Finally, we discuss the participants' views of the 'designer baby' debate. Scenarios in which the $\mathrm{D} /$ deaf and hearing purposefully select then terminate the 'wrong' hearing status child were first of all, quite unheard of for our participants, and then, when it was explained to them, considered to be an abhorrent practice. In the process of systematically reviewing the international literature in which these questions have been asked of other larger populations of the $\mathrm{D} /$ deaf and hearing, we could find no studies in which any more than a small percentage of people questioned would consider engaging in such practices. Why it is then, that deafness is so frequently cited as a prime example of the ethical dilemmas of 'designer babies' when the empirical data suggests that few people are interested in engaging in this use of genetic technologies? Gooding et al (2002) argue that it is because the practice of teaching bioethics lies in the selection of 'difficult' or 'extreme' cases and this applies to teaching the ethics of 
prenatal testing technologies. 'Extreme' examples can, for instance, be used to explore the class's hitherto untested assumptions about normalness, to startle a class into becoming more aware of new developments in science, to define the limits of parental decision-making, or to explore the role of professional gatekeepers of access to these techniques. While such learning outcomes are good things in themselves, the dilemma of this teaching style - according to Gooding et al (2002:38) - lies in the subtle unintended messages that such 'difficult' cases create about the types of disabilities which they feature. Because the focus is on the ethical reasoning created by 'unusual' requests for such technological intervention, the classes necessarily neglect to explore the ordinary lived context of life with these 'difficult' situations ie of achondroplasia or deafness and the wider scope of people's reproductive decision-making. Instead, these scenarios commit what Parens and Asch (2000) have described as the sin of synecdoche in which the part is mistaken for the whole. They assume that parents with impairments consider only the topic of impairment when they think of the complex situation of having a family and nothing else. From the stories that we have been privileged to hear in our own project, this seems quite unlikely. The disabling assumptions behind certain bioethical theories have also been well critiqued by philosopher Jackie Leach Scully (2008) - a person who is herself hard of hearing. Kermit (2010) has similarly discussed the oversimplification of ethical arguments around the ethics of cochlear implant choices and the construction of $\mathrm{D} /$ deafness in bioethical discourses on the topic.

\section{CONCLUSION}

Underscored through all of the participants' quite different journeys into family life was the overriding principle that to be $\mathrm{D} /$ deaf was to be an example of perfectly normal and acceptable human variation in form. Care, love, responsibility, unconditional welcome of the newborns, and the aspiration to create the best life possible for their children regardless of whichever communicative strategies were eventually chosen, emerged strongly in each family's story of how they approached reproductive decision-making. There was recognition that all folk need a little help at some time, as much as they also benefit from developing their capacity for self-reliance, and there was always a certain unevenness in life's trajectory for one's children despite the very best of planning and preparation.

Thinking outwards from the family towards decisions that other parents might make about prenatal testing and deafness, some of the young adults in the families hesitantly considered the 'right to choose' might be applicable as an 
ethical principle. The strongest ethical issues, however, for these three families by far, were not about the uses of genetics for reproductive decision-making. Instead, the issues were about negotiating whether or not to consider cochlear implants for their children, how to respond to the systemic social injustice of the lack of adequately trained support teachers for their children, and how to respond to the discriminatory attitudes of the wider general public.

\section{ACKNOWLEDGEMENTS}

Our thanks to the participating families in this project and also for the financial support to the wider project provided by the Marsden Fund administered by the Royal Society of New Zealand.

\section{NOTES}

1 Grant Details: 'Troubling Choice. Exploring and explaining techniques of moral reasoning for people living at the intersection of reproductive technologies, genetics, and disability', \$NZ 735,000, Feb 201-Feb 2014. (PIs Assoc. Prof. Ruth Fitzgerald, University of Otago, Prof. Julie Park, University of Auckland, and Assoc. Prof. Mike Legge, University of Otago).

\section{REFERENCES}

ACART. 2008 Committee Advice on Preimplantation Genetic Diagnosis. Retrieved from http://www.acart.health.govt.nz/moh.nsf/indexcm/acart-workprogrammeassisted

ввс News. 2002 April 8 Couple 'choose' to have deaf baby. ввс News.

Best, A., Howland, C., Snapp, J. and Park, J. 2013 Eugenics and utopia: social imaginaries of technologies for deafness. Sites $10(2)$ :

Bird, P., Botting, A., Milburn, J., Murray, D., \& Heslop, N. 2010 An audit of referrals to the Southern Cochlear Implant Paediatric Programme. The New Zealand Medical Journal, 123(1313):10-14.

Boudreault, P., Baldwin, E.E., Fox, M., Dutton, L., Tullis, L., Linden, J., Kobayashi, Y., Zhou, J., Sinsheimer, J., Sininger, Y., Grody, W., \& Palmer, C.G.S. 2010 Deaf Adults' Reasons for Genetic Testing Depend on Cultural Affiliation: Results From a Prospective, Longitudinal Genetic Counseling and Testing Study. Journal of Deaf Studies and Deaf Education, 15(3):209-227. doi:10.1093/deafed/enq012 
Broad, R. 2012 Conversations about postlingual deafness, disability and cochlear implants: A South Island family study. (Hons Diss.) University of Otago, Dunedin, New Zealand.

Burton, S.K., Withrow, K., Arnos, K.S., Kalfoglou, A.L., \& Pandya, A. 2006 A focus group study of consumer attitudes toward genetic testing and newborn screening for deafness. Genetics in Medicine, 8(12):779-783.

Clift, K.E. 2012 Glimpses of Eternity: some New Zealand Mormon understandings of disability, genetic testing and reproductive choice (MA). University of Otago, Dunedin, New Zealand.

Du Plessis, R., \& P. Fairbairn-Dunlop 2009 The ethics of knowledge production: Pacific challenges. International Social Science Journal 6o(195):109-114.

Fahmy, M.S. 2011 On the supposed moral harm of selecting for deafness. Bioethics, 25(3): $128-136$.

Fitzgerald, R.P. 2008 Biological Citizenship at the Periphery: parenting children with genetic disorders, New Genetics and Society 27(3):251-266.

Fu, S., Dong, J., Wang, C., \& Chen, G. 2010 Parental attitudes toward genetic testing for prelingual deafness in China. International Journal of Pediatric Otorhinolaryngology, 74(10):1122-1125. doi:10.1016/j.ijporl.2010.06.012

Gooding, H.C., Wilfond, B. S., Boehm, J., \& Biesecker, B. B. 2002 Unintended Messages: The ethics of teaching genetic dilemmas. Hastings Center Report, 32(2):37-39.

Guillemin, M., \& Gillam, L. 2006 Attitudes to Genetic Testing for Deafness: The Importance of Informed Choice. Journal of Genetic Counseling, 15(1):51-59. doi: $10.1007 /$ s10897-005-9003-6

Hammersley, M., \& Atkinson, P. 2007 The process of analysis. In Ethnography: Principles in Practice. London: Routledge:158-190.

HART Act. 2004 Parliamentary Counsel Office. Human Assisted Reproductive Technology Act 2004. Retrieved from http://www.legislation.govt.nz/act/public/2004/oog2/latest/whole.html.

Kermit, P. 2010 'Hearing' or 'Deaf'? Discussing epistemological and methodological issues related to the bioethical discourse on paediatric cochlear implantation. 
Scandinavian Journal of Disability Research, 12(2): 91-107.

Kochhar, A., Hildebrand, M.S., \& Smith, R.J.H. 2007 Clinical aspects of hereditary hearing loss. Genetics in Medicine, 9(7):393-408. doi:10.1097/ GIM.obo13e318098obdo

McKee, R. 2006 Connecting Hearing Parents with the Deaf World. Sites, 3(1):143-167.

Middleton, A. 2004 Deaf and hearing adults' attitudes toward genetic testing for deafness.pdf. In J. V. Van Cleve (Ed.), Genetics, Disability, and Deafness. Washington DC: Gallaudet University Press:127-147.

Noble, R. 2006 My Mum is Deaf. Sites, 3(1): 205-213.

Parens, E., \& Asch, A. 2000 Prenatal Testing and Disability Rights. Washington, D.C.: Georgetown University Press.

Parker, M. 2007 The best possible child. Journal of Medical Ethics, 33(5):279-283.

Parsons, T. 1971 The System of Modern Societies. Englewood Cliffs, NJ: Prentice Hall.

Ralston, D.C., \& Ho, J. 2007 Disability, humanity and personhood: a survey of moral concepts. Journal of Medicine and Philosophy, 32: 619-633.

Ryan, M., Miedzybrodzka, Z., \& Fraser, L. 2003 Genetic information but not termination: pregnant women's attitudes and willingness to pay for carrier screening for deafness genes. Journal of Medical Genetics, 40(6):1-5.

Sabatello, M. 2009 The Politics of a Child's Right to Identity in a Disability-Free Society. International Journal of Children's Rights, 17:177-206.

Savulescu, J. 2002 Deaf lesbians, 'designer disability', and the future of medicine. British Medical Journal, 325:771-773.

Scott, A. \& Du Plessis, R. 2008 Eliciting situated knowledges about new technologies. Public Understanding of Science 17(1):105-119.

Scott, A. and Du Plessis, R. 2008 Redefining a technology: Public and private genetic testing in Aotearoa New Zealand. Sociology of Health \& Illness 30(3):364-379. 
Scully, J.L. 2008 Disability Bioethics: Moral Bodies, Moral Difference. Lanham: Rowman \& Littlefield.

Shaw, D. 2008 Deaf by design: disability and impartiality. Bioethics, 22(8): 407-413.

Smiler, K. 2006 Maori Deaf Identity. Sites, 3(1):108-125.

Spriggs, M. 2002 Lesbian couple create a child who is deaf like them: a deaf lesbian couple who chose to have a deaf child receive a lot of criticism. Journal of Medical Ethics, 28(5): 283 .

Steinberg, A.G., Kaimal, G., Bain, L., Krantz, I., \& Li, Y. 2007 Parental narratives on genetic testing for children with hearing loss: A qualitative inquiry. American Journal of Medical Genetics Part A, 143A(14):1533-1545. doi:10.1002/ajmg.a.31731

Taneja, P.R., Pandya, A., Foley, D., Nicely, L.V., \& Arnos, K.S. 2004 Attitudes of Deaf Indivuals towards Genetic Screening. American Journal of Medical Genetics, 13OA: 17-21. 